\title{
Ear Embryology
}

\section{* Ghada M Wageih Felfela}

Doctor of Audiology-Health Insurance, Cairo University, Egypt

Submission: February 04, 2017; Published: February 20, 2017

*Corresponding author: Doctor of Audiology-Health Insurance, M Sc of Audio-Vestibular medicine, Faculty of Medicine, Cairo University, Egypt.

\section{Embryology}

It is the study of the origin and development of single individual (embryo) in prenatal period.

\section{Embryonic period}

i. $\quad$ First 8 weeks (56 days).

ii. Fetal period - remaining 30 weeks (210 days) (Figure 1).

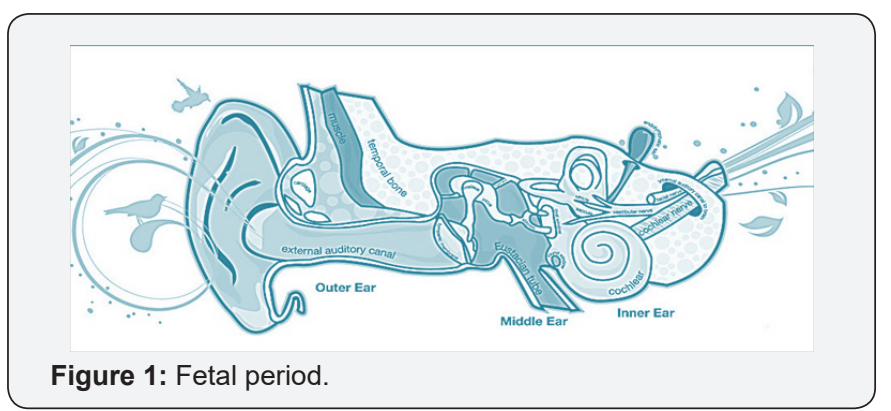

Development of different parts of the ear

\section{Outer ear}

a. Pinna arises from fusion of six auricular hillocks.

b. External auditory meatus is ectoderm of first pharyngeal cleft.

TM ->Inner layer "endoderm", Middle layer "mesoderm" and Outer layer "ectoderm".

\section{Middle ear}

a. Middle ear cavity and Eustachian tube $->$ from first pharyngeal pouch endoderm.

b. Middle ear ossicles come from first (malleus and incus) and second (and stapes) pharyngeal arches mesoderm.

Inner ear and the formation of the membranous labyrinth

a. Membranous labyrinth: derived from ectodermal invagination from otic placode.

b. Bony labyrinth: from mesoderm (Figure 2).

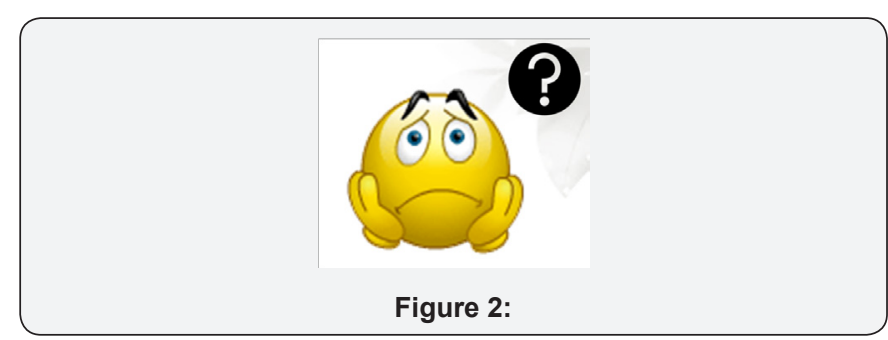

\section{Stages of Development}

Sperm (23 chromosome)penetrates the -> ovum (23ch.) , forming -> Zygot (46 ch.) -> by mitosis -> 2,4,6,...(within 96 hours).... 30 cells $->$ forming morula (Blastomere) (Figure 3).

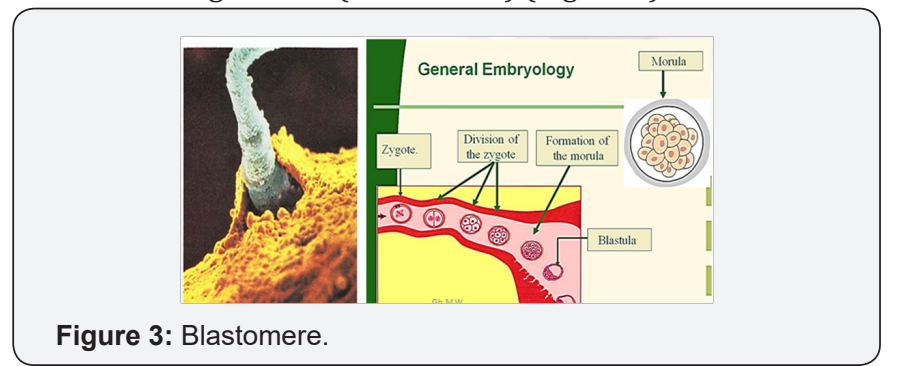

On the $4^{\text {th }}$ day, Blastocyst is formed:

a. Embryoblast at one pole.

b. Surrounded by pellucid zone.

c. Outer trophoblast -> will form the infantile part of the placenta and the fetal membranes.

d. Inner Blastocyst cavity (filled by fluid $->$ nutrition and protection) (Figure 4).

Figure 4: Inner Blastocyst cavity.




\section{Global Journal of Otolaryngology}

At the end of the $6^{\text {th }}$ day, blastocyst then hatches from the pellucid zone à and moves until it embeds in the endometrium.

The trophoblast differentiates into two different cell masses, shortly before it comes into contact with the endometrium:

a. The outer syncytiotrophoblast (ST) -> develops quickly and will entirely surround the embryo as soon as it has completely embedded itself in the endometrium.

b. The inner cytotrophoblast (CT) (Figure 5).

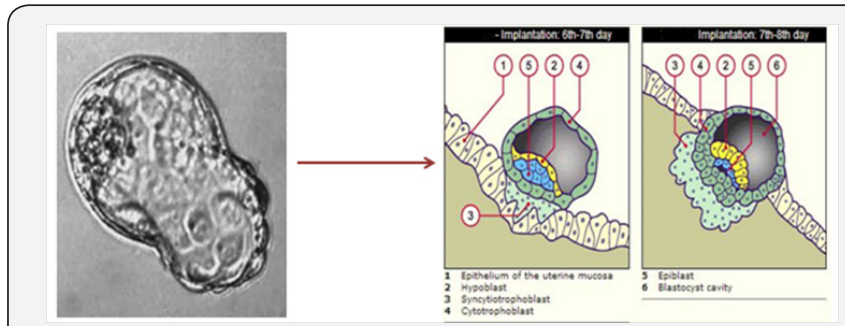

Figure 5: Inner cytotrophoblast.

Blastocyst is now completely implanted within the endometrium.

Amniotic cavity begins to develop within epiblast cells zone.

Hypoblast cells begin to multiply (Figure 6). Previous Embryoblast
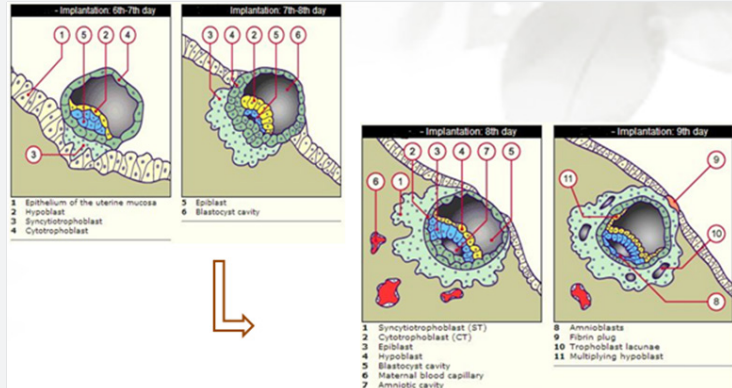

Figure 6: Hypoblast cells begin to multiply.

At the end of $2^{\text {nd }}$ week: "Double-layered embryonic disc" is formed (Figure 7).

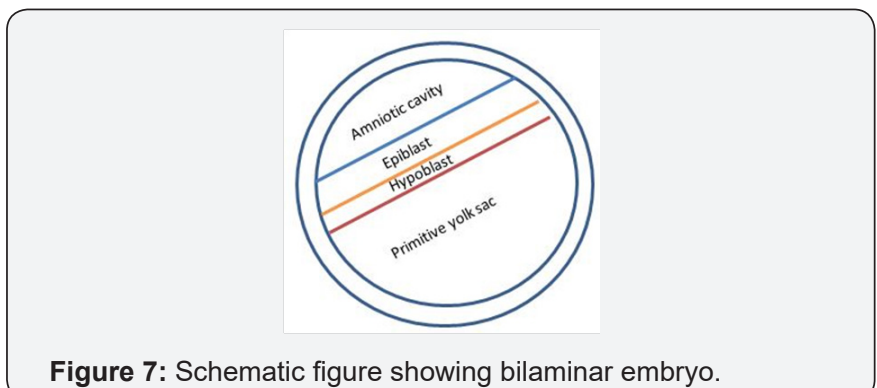

Gastrulation Stage: during which "Trilaminar embryo" is formed. HOW?!!!

i. A primitive streak is formed through ectoderm (previous epiblast) through which ectoderm cells migrate forming mesodermal layer and endoderm too (Figure 8).

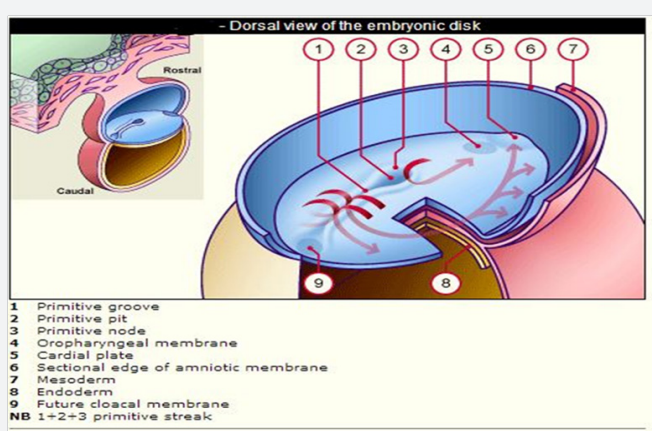

Figure 8: Dorsal view of the embryonic disk.

ii. From the $17^{\text {th }}$ day, primitive streak lengthens until it occupies half the embryo.

iii. After the $19^{\text {th }}$ day, at the anterior end, a groove forms in the ectoderm -> primitive groove. The cranial region $->$ forms the primitive pit.

iv. The head of the embryo will form at the extremity of the embryonic disk near the primitive pit.

v. The notochord is formed through mesoderm and determines the longitudinal axis of the embryo à future vertebral body (Figures $9 \& 10$ ).

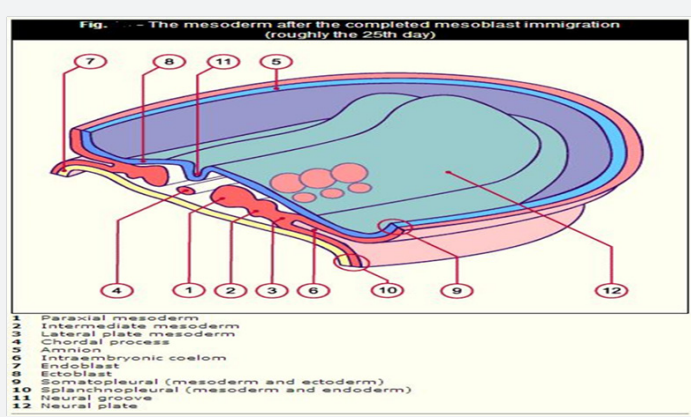

Figure 9: The mesoderm after the completed mesoblast immigration (roughly the 25th day).

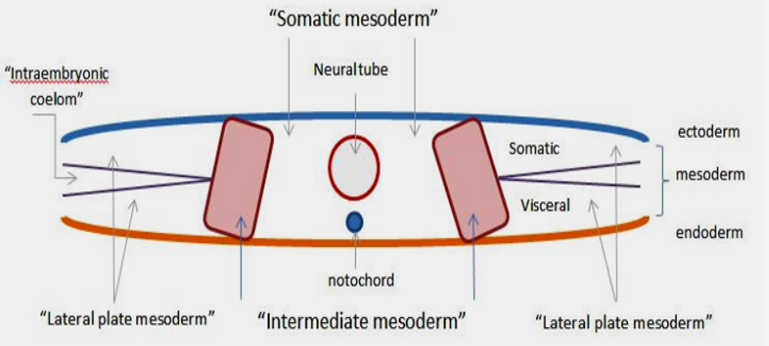

Figure 10: Formation of Mesoderm layer.

a. Neural tube $->$ Brain, brain stem, spinal cord and all nervous systems. 
b. Somatic mesoderm -> somites.

c. Intermediate mesoderm -> gonads and kidney.

d. Lat plate mesoderm -> visceral portion ->gut tube and surrounding smooth $\mathrm{m}$. and connective tissue.

e. $\quad->$ Somatic portion -> Body wall (thoracic cage, abdominal wall and most of anterior wall of pelvis) (Figures $11 \& 12)$.
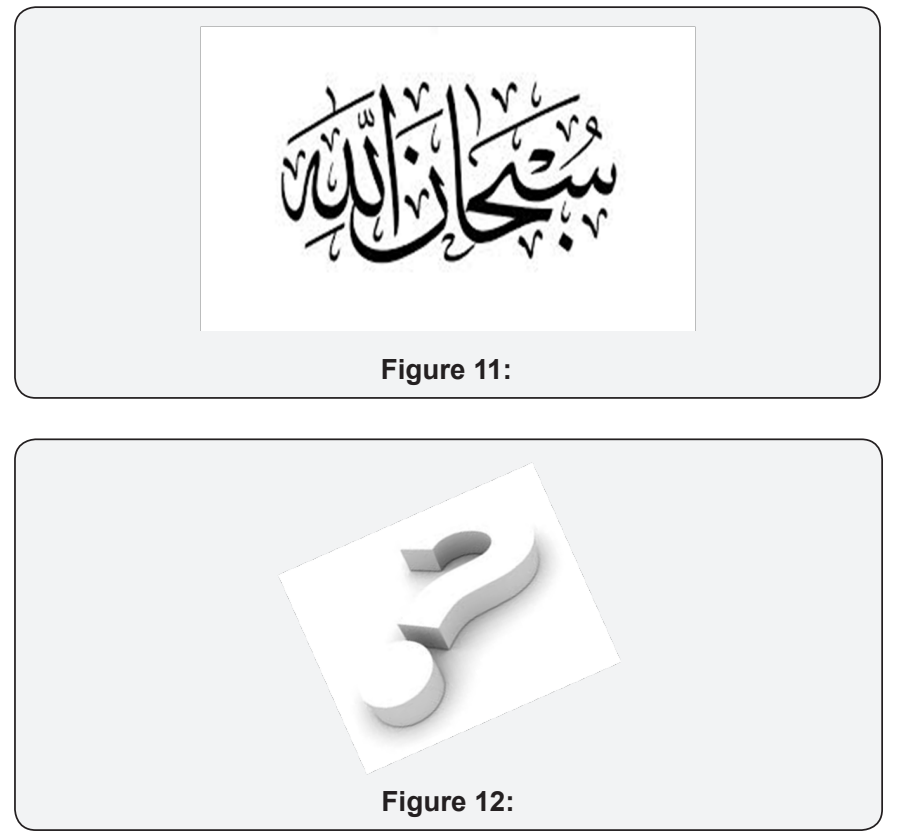

\section{Inner Ear Development}

Early in the $4^{\text {th }}$ week, a thickening of the surface ectoderm on each side of the hindbrain -> otic placode -> otic pit $->$ form the otic (auditory) vesicle à membranous labyrinth. Each vesicle divides into:

I. The ventral component -> saccule and the cochlear duct (scala media)

II. The dorsal portion -> utricle, semicircular canals and endolymphatic duct and sac (Figures 13 \& 14).

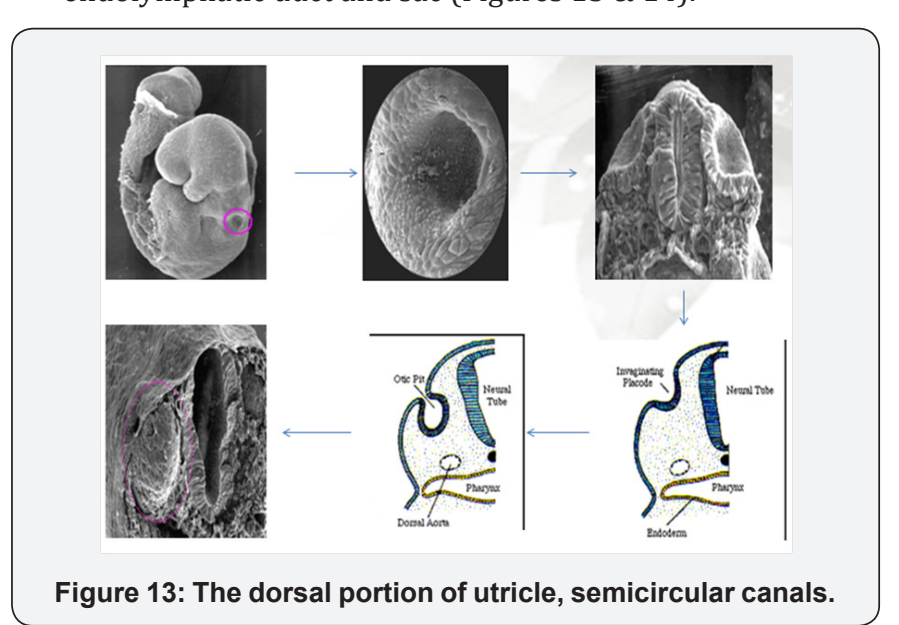

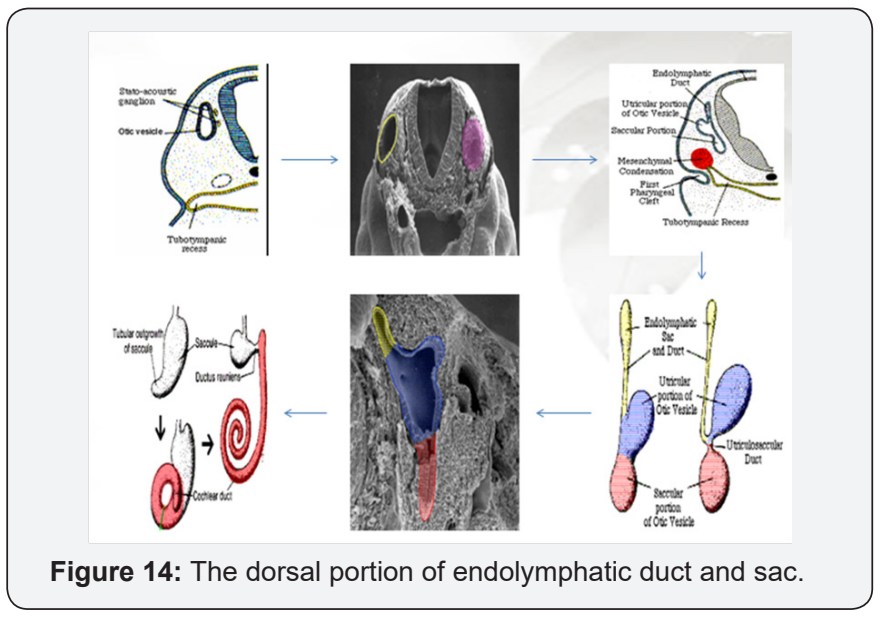

\section{Saccule, Cochlea, and Organ of corti}

a. In the $6^{\text {th }}$ week of development: saccular lower pole -> the cochlear duct $\rightarrow$ penetrates surrounding mesenchyme in a spiral fashion -> completed 2.5 turns at the end of the $8^{\text {th }}$ week. And the ductus reuniens connects the saccule with utricle.

b. Mesenchyme surrounding the cochlear duct -> forming cartilage.

c. In the $10^{\text {th }}$ week, this cartilaginous shell undergoes vacuolization, and two perilymphatic spaces, the scala vestibuli and scala tympani.

d. The vestibular membrane separates cochlear duct from the scala vestibuli.

e. The basilar membrane separates cochlear duct from the scala tympani.

f. The spiral ligament attaches lateral wall of the cochlear duct to the surrounding cartilage.

g. The median angle of the cochlea duct is connected to and partly supported by a long cartilaginous process, the modiolus -> the future axis of the bony cochlea (Figure15).

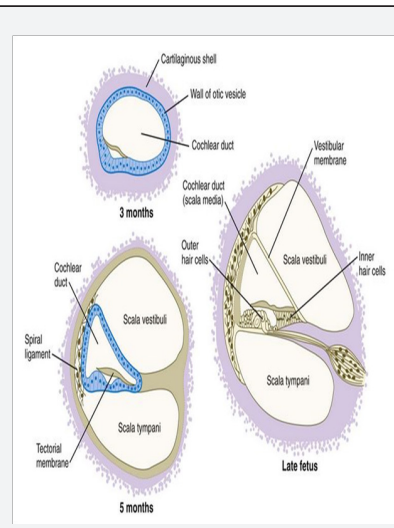

Figure 15: Future axis of the bony cochlea. 
h. The epithelial cells of the cochlear duct form two ridges:

i. The inner ridge, the future spiral limbus,

j. The outer ridge which forms the sensory hair cells

a) *ne inner row,

b) *Three or four outer rows.

k. They are covered by the tectorial membrane.

l. The sensory cells + tectorial membrane ->constitute the organ of Corti.

m. Impulses received by this organ $\rightarrow$ the spiral ganglion to $->$ the nervous system by the auditory fibers of $8^{\text {th }}$ cranial nerve.

n. The capsular cartilage serves as a template for the later formation of the true bony labyrinth. The conversion from the cartilaginous to the bony labyrinth occurs between 16 and 23 weeks' gestation (Figure16).

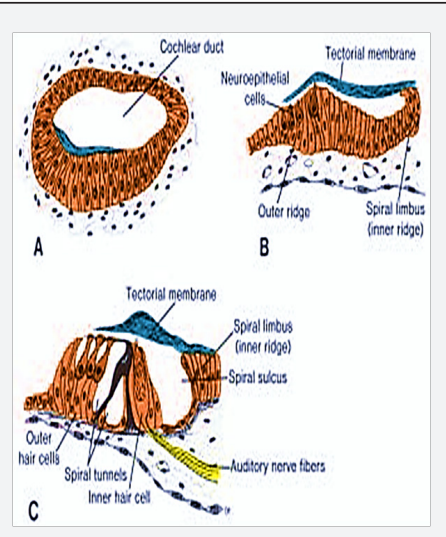

Figure 16: Conversion from the cartilaginous to the bony labyrinth occurs between 16 and 23 weeks' gestation.

\section{Utricle and Semicircular canals}

a. During the $6^{\text {th }}$ week of development, semicircular canals appear as flattened outpocketings of the utricular part of the otic vesicle -> Central portions of the walls of them -> appose each other and disappear à giving rise to 3 SCC. ( Programmed cell death)

b. One end of each canal dilates -> form the crus ampullare, the other, the crus nonampullare, does not widen.

c. Five crura enter the utricle, three with an ampulla and two without.

d. Cells in the ampullae form a crest $->$ the crista ampullaris, containing sensory cells.

e. Similar sensory areas develop in the walls of the utricle and saccule. f. Impulses generated in sensory cells of the cristae and maculae as a result of a change in body position à the brain by vestibular fibers of VIII $\mathrm{cr}$.

g. The statoacoustic ganglion forms during formation of the otic vesicle à The ganglion splits into cochlear and vestibular portions (Figure17).

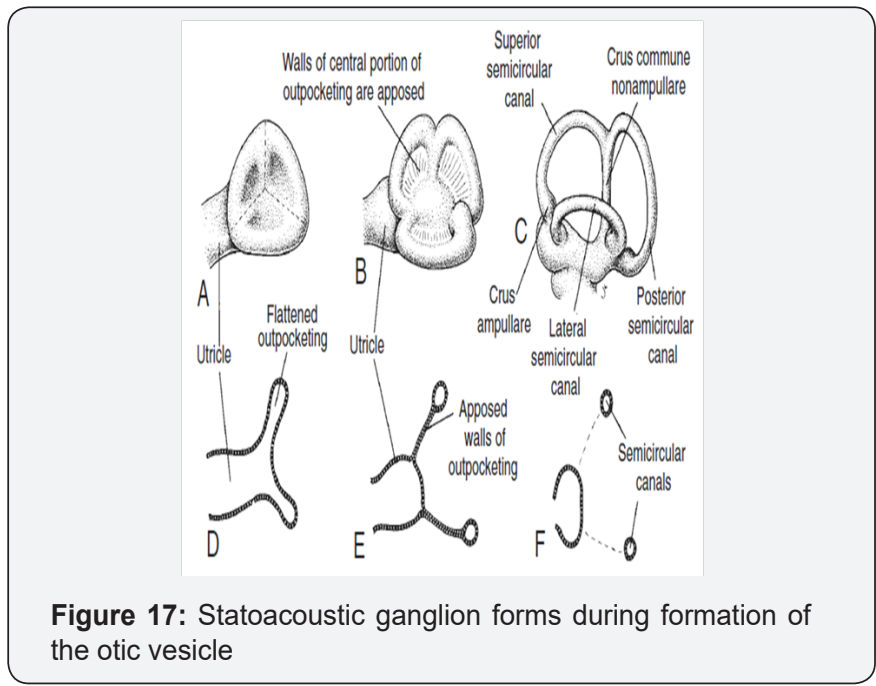

\section{Endolymphatic Duct and Sac}

The auditory vesicle elongates and develops an indenting groove, which demarcates a tubular diverticulum on its medial side -> which will be modified into the endolymphatic sac and duct, -> and continues to grow postnatally until the age of three or four years (Figure18).

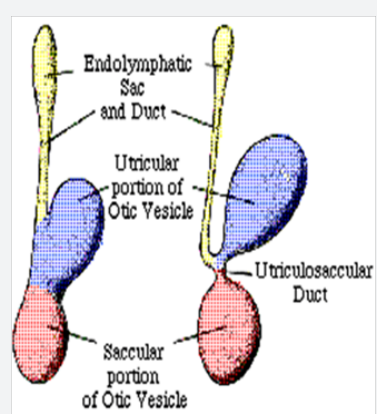

Figure 7: Schematic figure showing bilaminar embryo.

\section{Pharyngeal arches}

They are 5 arches developed by 23 days of gestation called mandibular arches in proximal portion of embryo, separated by pharyngeal grooves/clefts. They are 5 arches $1^{\text {st }}, 2^{\text {nd }}, 3^{\text {rd }}, 4^{\text {th }}$ and $6^{\text {th }}$. The $5^{\text {th }}$ arch did not develop in human but in other species. Each arch is formed from:

i. Ectoderm: -> skin of head and neck region.

ii. Endoderm: -> lining for oral, nasal, pharyngeal and Eustachian tube.

iii. Mesoderm: core of each arch (Figure19). 


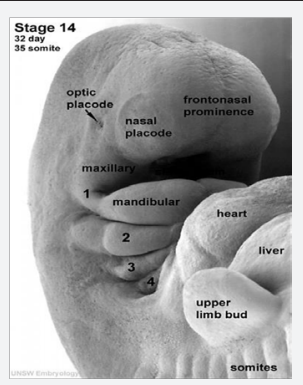

Figure 19: Mesoderm: core of each arch-stages of mesoderm.

\section{Summary-Pharyngeal Arches}

$1^{\text {st }}$ Pharyngeal Arch

a. Innervated by CN V

b. Muscles of mastication, tensor palatine, tensor tympani, mylohyoid, anterior belly of digastric muscle,

c. Maxilla, mandible, malleus, and incus.

$2^{\text {nd }}$ Pharyngeal Arch

a. Innervated by CN VII

b. Muscles of facial expression, stapedius, stylohoid, posterior belly of digastric muscle,

c. Stapes, styloid, and part of hyoid bone $3^{\text {rd }}$ Pharyngeal Arch
a. Innervated by CN IX
b. One pharyngeal muscle- stylopharyngeus m.
c. Body and greater horn of hyoid bone

$4^{\text {th }}$ and $6^{\text {th }}$ Pharyngeal Arches
a. $\quad 4^{\text {th }}$ arch Innervated by CN X
b. $6^{\text {th }}$ arch Innervated by recurrent laryngeal nerve from CN X

c. Pharyngeal and Laryngeal muscles: Swallowing and phonation

d. Laryngeal cartilages (Figures 20 \& 21)

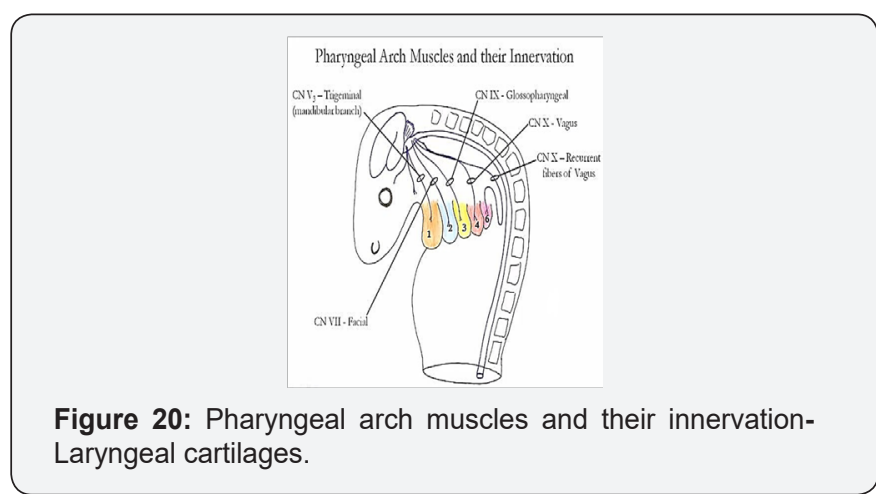

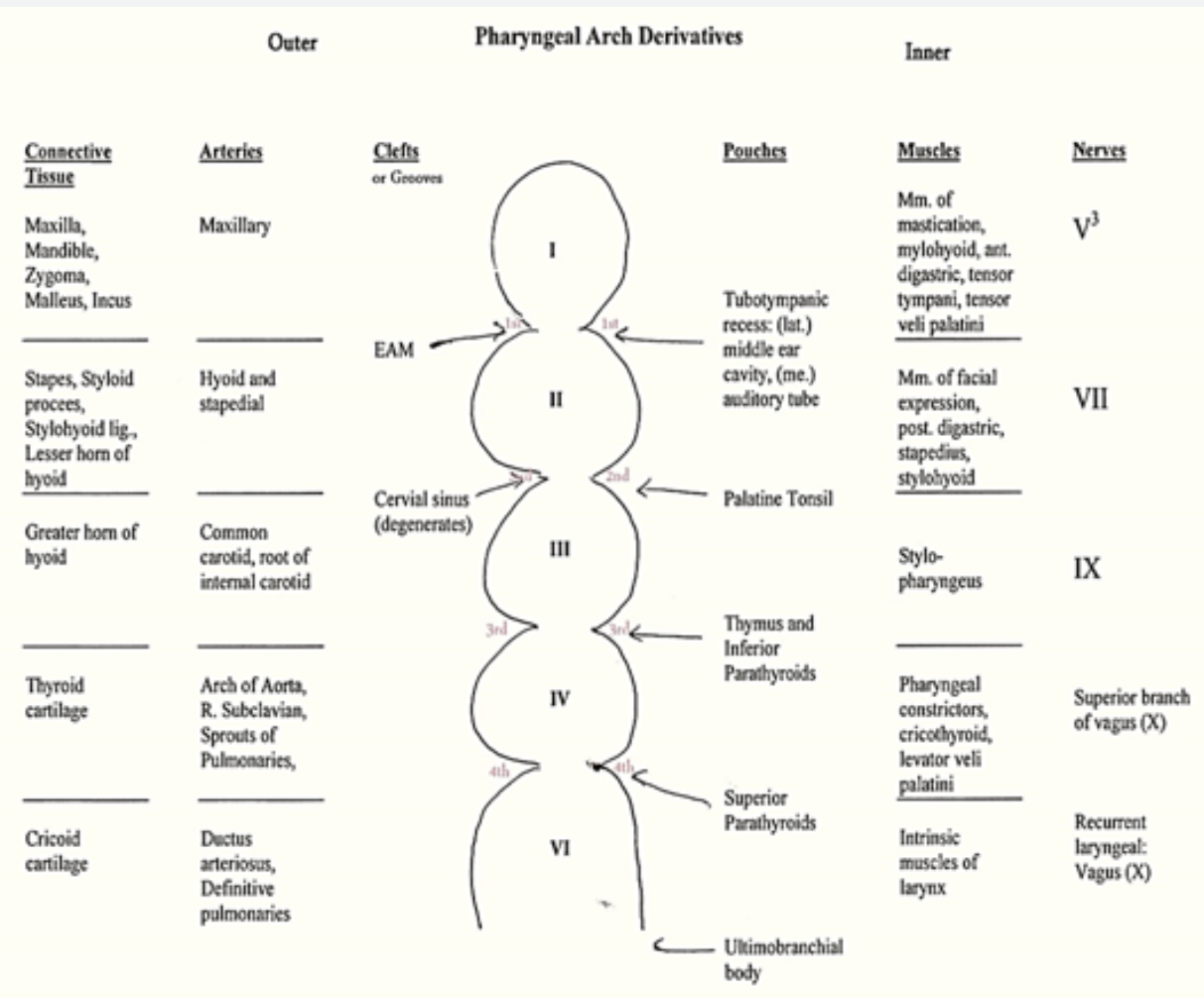

Figure 21: Pharyngeal arch muscles and their innervation- Laryngeal cartilages. 


\section{Middle Ear development}

i. The middle ear cavity and the auditory tube arise from -> first pharyngeal pouch called the tubotympanic sulcus, so -> lined with an endoderm.

ii. This pouch expands in a lateral direction and comes in contact with the floor of the first pharyngeal cleft.

iii. The distal part -> forming the tubotympanic recess.

iv. The proximal part -> the auditory tube (Eustachian tube) (Figure 22).

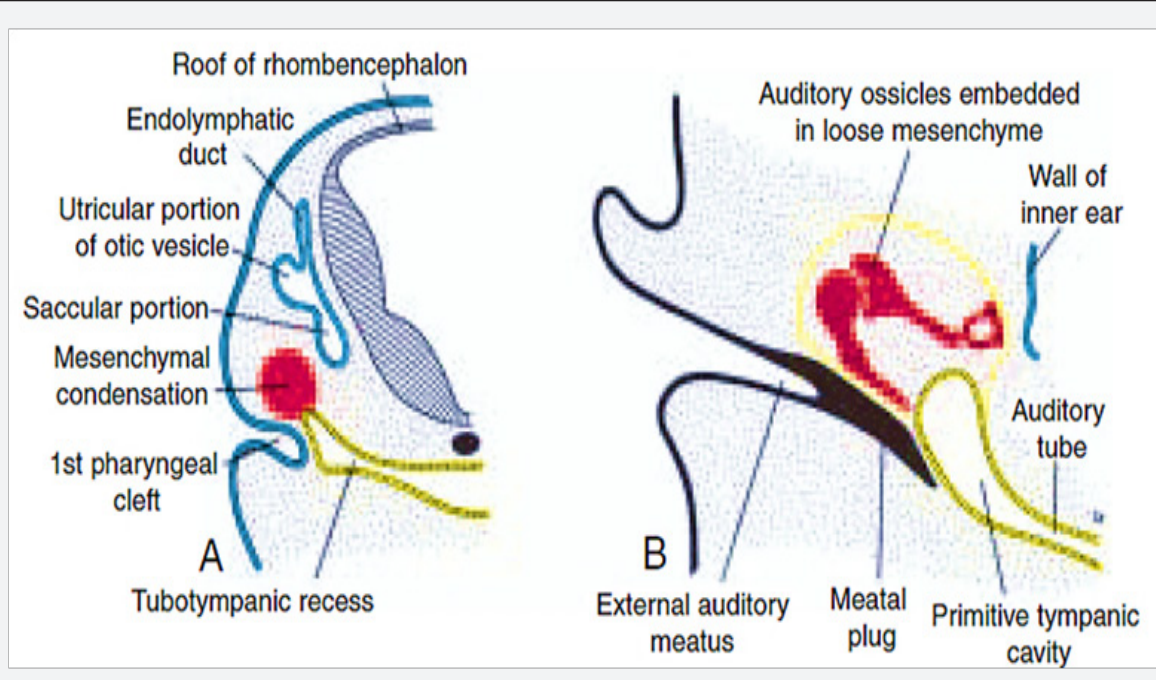

Figure 22: The proximal part of auditory tube.

v. Later, the endodermal epithelium of the tubotympanic sulcus becomes close to the ectoderm lining the first pharyngeal cleft, separated by mesoderm. This complex forms the tympanic membrane (eardrum). During fetal life, a prominent ring-shaped, called the tympanic ring, supports the tympanic membrane. Later, the tympanic ring becomes absorbed into the temporal bone.

vi. Just dorsal to the end of the tubotympanic sulcus, a condensation of mesenchyme -> appears at $6^{\text {th }}$ weeks $->$ form the middle ear ossicles. The malleus and incus arise from mesenchyme of the $1^{\text {st }}$ pharyngeal arch, whereas the stapes $->$ from $2^{\text {nd }}$ arch. The tensor tympani muscle, which is attached to the malleus -> from first-arch mesoderm, so ->innervated by trigeminal nerve ( $\mathrm{cr} \mathrm{n} \mathrm{V}$ ). The stapedius muscle $->$ is of second-arch origin, and is innervated by the facial nerve (cr n VII).

vii. Ossicles -> lie in a bed of very loose embryonic connective tissue; extend from the inner layer of the tympanic membrane to the oval window of the inner ear. The future middle ear cavity remains filled with loose mesenchyme until late in pregnancy.

viii. During the $8^{\text {th }}$ and $9^{\text {th }}$ months, programmed cell death and other resorptive processes -> clear the middle ear cavity and leave the auditory ossicles suspended within it. Free movement of the auditory ossicles is acquired within 2 months after birth.

ix. During late fetal life, the tympanic cavity expands dorsally by vacuolization of surrounding tissue to form the tympanic antrum. And After birth, epithelium of the tympanic cavity invades bone of the developing mastoid process. Later, most of the mastoid air sacs come in contact with the antrum and tympanic cavity.

\section{Development of the External Ear}

i. The external auditory meatus à first pharyngeal cleft.

ii. At the $3^{\text {rd }}$ month, epithelial cells at the bottom of the meatus proliferate, forming a solid epithelial plate, the meatal plug.

iii. In $7^{\text {th }}$ month, this plug dissolves and the epithelial lining of the floor of the meatus participates in formation of the definitive eardrum.

iv. Occasionally the meatal plug persists until birth, resulting in congenital deafness (Figure 23).

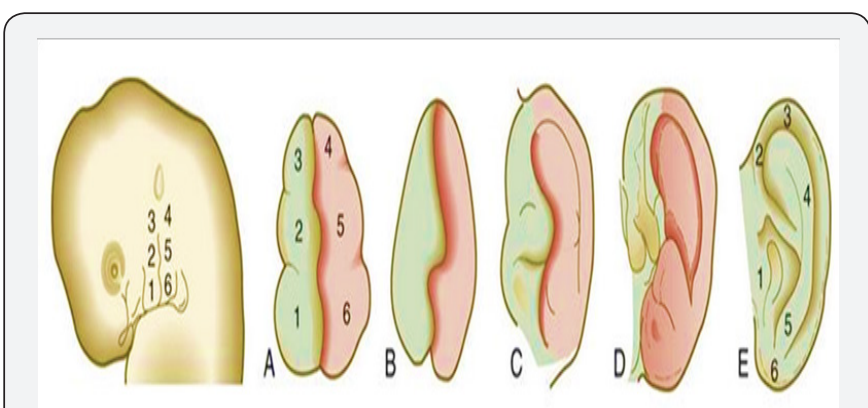

Figure 24: The first and second arches in pharyngeal region. 


\section{Global Journal of Otolaryngology}

\section{Development of Auricle}

i. By the end of $4^{\text {th }}$ week, the auricle develops from 6 mesenchymal proliferations (hillocks) of $1^{\text {st }}$ and $2^{\text {nd }}$ pharyngeal arches, surrounding the first pharyngeal cleft.

ii. These swellings (auricular hillocks), three on each side of the external meatus, later fuse and form the definitive auricle.

iii. As fusion of the auricular hillocks is complicated, developmental abnormalities of the auricle are common. iv. Initially, the external ears are in the lower neck region, but with development of the mandible, they ascend to the side of the head at the level of the eyes.

v. Because of its association with the pharyngeal arches, the external ear is a sensitive indicator of abnormal development in the pharyngeal region. Other anomalies of the first and second arches are often attended by abnormally located external ears (Figures $24 \& 25$ ).
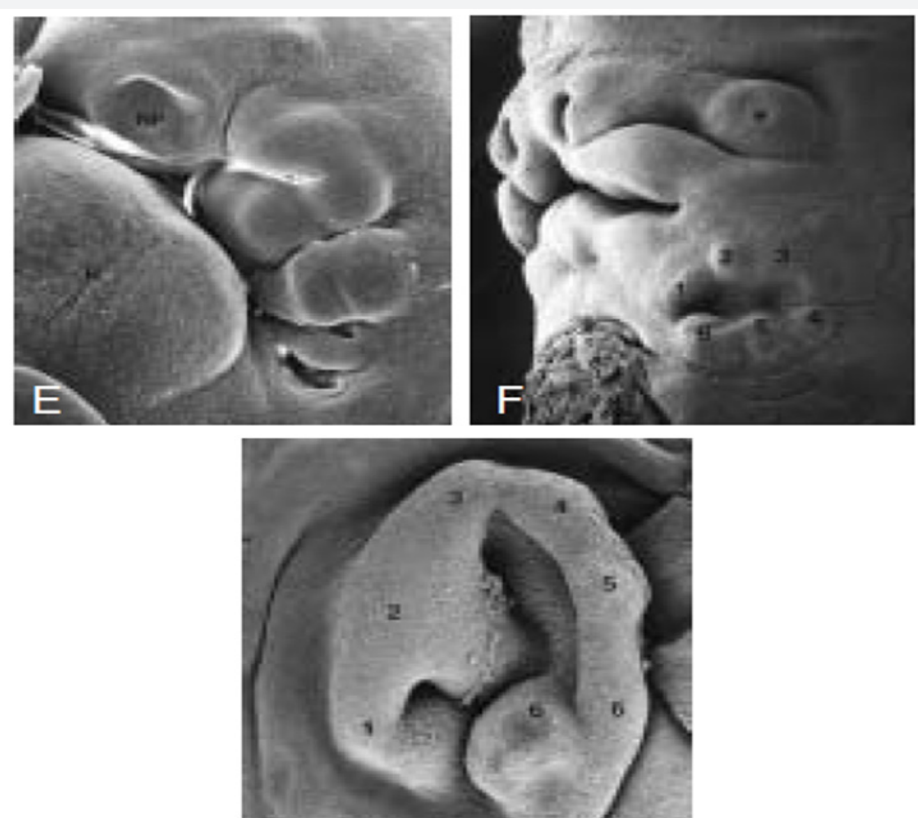

Figure 25: Notice ear-mouth relation
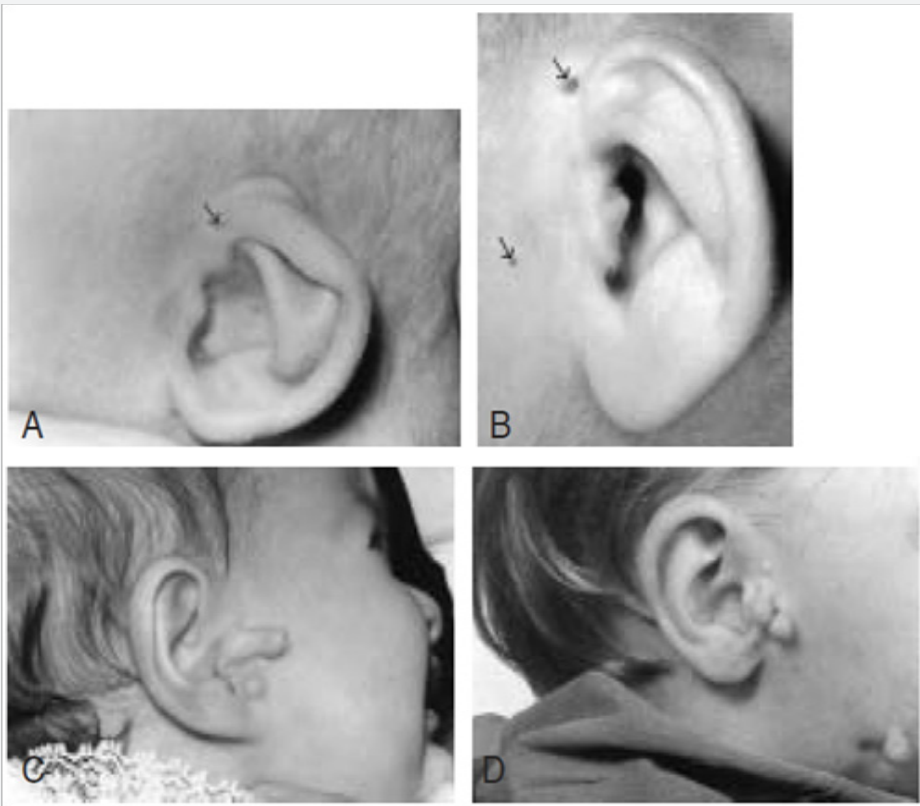

Figure 26: Exposure to excess retinoic acid or derivatives commonly results in anomalies of the external ear. 


\section{Congenital Deafness}

a. For example rubella can lead to maldevelopment of the organ of Corti.

b. Abnormalities of the middle ear ossicles or ligaments, which can be associated with anomalies of the $1^{\text {st }}$ and $2^{\text {nd }}$ arches.

c. Mutants, such as those of Pax-3 causing variants of Waardenburg's syndrome, can affect development at levels ranging from gross morphogenesis of the ear to specific cellular defects in the cochleosaccular complex.

\section{Auricular Anomalies}

a. Because of the multiple origins of its components -> pinna malformations such as

b. Auricular appendages, or sinuses, low set ear, Bat ear, accessory auricle.

c. May be associated with other developmental anomalies, such as malformations of the kidneys and pharyngeal arches. Exposure to excess retinoic acid or derivatives commonly results in anomalies of the external ear (Figure 26).

\section{Your next submission with Juniper Publishers} will reach you the below assets

- Quality Editorial service

- Swift Peer Review

- Reprints availability

- E-prints Service

- Manuscript Podcast for convenient understanding

- Global attainment for your research

- Manuscript accessibility in different formats ( Pdf, E-pub, Full Text, Audio)

- Unceasing customer service

Track the below URL for one-step submission https://juniperpublishers.com/online-submission.php 